\title{
"Tommy goes out into the night to seek an elf": o (des-)tecer e o (des-)dizer do sujeito nas obras de Robert Duncan e de Jess
}

Resumo: Partindo do pensamento de Richard Feynman acerca do significado de tudo e das noções de entalpia e entropia, este texto procura discutir a questão da construção da identidade pela negativa - um des-tecer e des-dizer de si - nas obras do poeta Robert Duncan e do seu companheiro, o químico e pintor Jess (Collins). Numa poética, a um tempo, política e sexual, ambos os artistas tentam lidar com a violência da linguagem na construção de um modelo de representação que não tem outra opção que não seja a de confrontar o discurso hegemónico (como modo de lutar contra "formas para libertar a Forma", como diria Duncan). Ambos os artistas lidam com a apreensão da luz (beleza/conhecimento/sabedoria) na escuridão, apanhando os fragmentos de um Todo (seja este a nação, a comunidade, o amor ou o próprio Cosmos), que é sempre inalcançável e que, contudo, se sabem a nele participar, no seu movimento, "It". O seu projecto comum de uma grand collage constrói uma consciência radical da alteridade e da performatividade que usa uma linguagem metonímica e inclusiva como construção democrática do real.

Palavras-chave: Identidade, sexualidade, política, modelos de representação, ciência, entalpia, entropia, "It"

Abstract: Starting from Richard Feynman's ideas on the meaning of it all and the notions of enthalpy and entropy, this paper discusses the question of an identity negative construction - an unweaving and unsaying of the self - in the works of poet Robert Duncan and his life-companion, the Chemistry graduate, and painter, Jess (Collins). In a political and sexual poetics, both artists deal with the violence of language in the construction of a model of representation that has no option but to confront the hegemonic discourse (as a way of struggling "with forms to liberate Form", as Duncan would put it). Both artists deal with the catching of light (beauty/knowledge/ wisdom) in the darkness, catching the fragments of a Whole (be it nation, community, love, or the Cosmos itself) that is permanently unreachable, and, yet, they know they are participating in its movement, in "It". Their joint project of a grand collage composes a radical consciousness of alterity and performativity that takes a metonymic all-inclusive language as a democratic construction of the real.

Keywords: Identity, sexuality, politics, models of representation, science, enthalpy, entropy, "It" 
Escrever este texto obrigou-me a regressar a algumas temáticas que, no meu já longo percurso e de forma inevitável, fui tocando aqui e ali, mas que, em rigor, nunca se constituíram como cerne da minha pesquisa. Obrigando a colocar-me, ou a recolocar-me, na minha renovada ignorância, tal ensejo deu-me a oportunidade de começar, também de novo, a sentir o entusiasmo das primeiras perguntas. Estou assim a entrar, novamente, no espaço de aventura que parte do que também o físico teórico Richard Feynman chamou "uma filosofia da ignorância", num livro que leva por título, de forma só aparentemente paradoxal, O significado de tudo (Feynman 1998: 37) - um título de uma profunda ironia, como era hábito neste cientista responsável pela teorização da electrodinâmica quântica.

Partindo dessa ironia, tentarei aqui responder ao desafio que dois artistas norteamericanos, o poeta Robert Duncan e o seu companheiro de uma vida, o pintor Jess, me lançaram. Esse desafio irrompe do entendimento de que a construção da identidade a trindade de que Duncan fala como "Me-Myself-and-l" ("eu-me-mim") (Duncan 1985c: 219) - em termos termodinâmicos, atrevo-me a pensar, é um trabalho de estruturas e de passagens. De facto, no ensaio de Robert Duncan, "The Self in Postmodern Poetry" (publicado pela primeira vez em 1983, mas escrito para um congresso em 1979), ensaio a que fui buscar o meu título e que trata da questão da identidade (poética, e não só), surge a expressão "the dissolution of the physical chemical universe" (Duncan 1985c: 233). Parece então que, nessa metáfora para a arquitectura do "Me-Myself-and-I", a energia interna do sistema, que é a identidade, se vai perdendo, pois que a forma resultante desse trabalho da mente surge enquanto esse "Me-Myself-and-I", a energia interna, se vai dissolvendo e se vai perdendo - como tudo no Todo que é o universo.

Como poderei então eu, vinda de uma área hierarquicamente menor nos discursos do saber, a das Artes e Humanidades, aceitar o desafio de Duncan e Jess, e, a partir das leis da termodinâmica e/ou do universo, tentar alcançar esse "significado de tudo", que sabemos nunca será totalizável? Aceitei o desafio porque, como diz Richard Feynman: "Se não fôssemos capazes ou não desejássemos olhar em novas direcções, se não tivéssemos dúvidas e não soubéssemos reconhecer a nossa ignorância, nunca chegaríamos a ter ideias novas" (Feynman 1998: 36). Considerando a hierarquia dos saberes instituída na nossa sociedade, ainda bem que é um físico reputado e não um poeta a dizê-lo... Feynman continua:

Aquilo a que hoje chamamos conhecimento científico é (...) [apenas] um corpo de afirmações com diversos graus de certeza. Algumas são muito incertas, outras são quase certas, mas nenhuma é absolutamente certa. (...) Algumas pessoas perguntam 'Como é que conseguem viver sem saber?' Não percebo o que querem dizer com isso. Sempre vivi sem saber. É fácil. 0 que quero saber é como é possível saber. (ibidem) 
Ou seja, não se trata de apenas fazer as perguntas, mas de saber como fazer as perguntas. Robert Duncan dizia que o que lhe interessava, mais do que a expansão da consciência humana, era saber como era possível a comunidade do humano ter expandido e continuar a expandir a sua consciência (Duncan 1985a: 8-9). E é aqui que o poeta e o físico parecem encontrar-se: nesse desejo de saber como é possível saber.

Para mim, o curioso foi observar que ambos colocaram as suas perguntas ao nível do "como": de que forma e em que forma podemos fazer as perguntas? Ou seja, ambos os autores falam de linguagem e de como, para chegarmos ao significado de tudo, teremos sempre de partir desse corpo de palavras, que é um corpo de representação - de nós próprios também. Aceitar isso significa, inevitavelmente, que todo o significado conseguido reside numa espécie de objectividade-fantasma da construção - artificial e performativa - que a linguagem significa na sua relação com o real (Taussig 2010). Por isso, aquilo a que chamamos "real" não passa de um "real-sempre-socialmente-construído". A ciência e a arte - os saberes e/ou os conhecimentos - não ficam fora dessa imagem, que se encontra dentro da moldura que tem o poder de enquadrar, como diria Foucault, ou seja, que tem o poder de legitimar as perguntas e/ou as representações que se devem ou podem fazer. É nessa radicalidade epistemológica que as perguntas primeiras se colocam: como saber como é possível saber, se já estamos dentro do sistema maior que já define o como do nosso saber?

Nesse nível de reflexão crítica se coloca, inexoravelmente, a dimensão política da ciência ou de qualquer outra forma de saber, a da arte incluída. Nessa dimensão política se coloca então, também, o como da construção do sujeito. Porque há representações que legitimamos como tendo significado e outras que ficam fora do espaço da comunidade - por serem um não-sentido ou um sentido-não. Trata-se de representações inaudíveis, invisíveis, interditas, sobre as quais, ou a partir das quais, se torna impossível (ou, pelo menos, muito difícil) formular as perguntas que nos poderiam levar ao que Feynman chama "ideias novas". Boaventura de Sousa Santos, falando dos saberes perdidos no processo violento que foi o colonialismo - e do como esses saberes esmagados nos teriam permitido formular (dar forma) a novas perguntas - fala de epistemicídios (Santos 2010). Robert Duncan, reportando-se também ao processo decorrente do colonialismo que é a nossa própria modernidade (um silenciamento de outros saberes e de outras perguntas possíveis), fala de uma moderna "magia da tribo":

But my point here is that the minuet, the game of tennis, the heroic couplet, the concept of form as the imposing of rules and establishing regularities, the theories of civilization, race, and progress, the performances in sciences and arts to rationalize the universe, to secure balance and class - all these are a tribal magic against a real threat of upset and things not keeping their place. (...) A change in mode, in what was permitted, once threatened demonic disorder. Now, unconventional usages threatened loss of reason or insurrection. (...) because thought must not wander, possibility must contain the reassurance of an end to possibilities (Duncan 1985b: 102) 
Neste sentido, de abrir a possibilidade para que todo um campo infinito de outras possibilidades possa emergir, Duncan proclama que a responsabilidade do poeta consiste na exigência de lutar contra a forma para poder libertar outras formas, desligitimando a linguagem dominante e entrando no espaço das novas perguntas:

It has seemed to me that I wrestle with the syntax of the world of my experience to bring forward into the Day the twisted syntax of my human language that will be changed in that contest even with what I dread there. And recently I have come to think of Poetry more and more as a wrestling with Form to liberate Form. (Duncan 1985a: 8)

Herdeiro de Duncan, para o bem e para o mal, também Charles Bernstein, filósofo e poeta, mentor da $L=A=N=G=U=A=G=E$ School, um movimento literário de vanguarda contemporâneo, chama a nossa atenção para esta necessidade do que chama um "pensamento tropical":

Poetry can bring to awareness questions of authority and conventionality, not to overthrow them, as in certain reading of destructive intent, but to reconfigure: a necessary defiguration as prerequisite for refiguration, for the regeneration of the ability to figure-count think figuratively, tropically. That poetry of which I speak is multidirectional and multivectorial; while some vectors are undermining others just keep on mining. (Bernstein 1992: 227)

Este espaço de excesso das perguntas e dos significados ainda por descobrir é um espaço em que a energia interna do sistema parece também ir-se perdendo ("my human language that will be changed in that contest even with what I dread there"; "while some vectors are undermining others just keep on mining"). A forma resultante desse trabalho da mente aparece também enquanto o "eu-me-mim", a energia interna, se vai dissolvendo e se vai perdendo. Entrar neste espaço agonista é entrar na violência da linguagem do (ainda-)silêncio (Lecercle 1990) - o espaço que é, simultaneamente, dos poetas e dos cientistas criativos, atrevo-me a dizer.

Trata-se então, nas palavras do poeta Robert Duncan, do espaço para também "des-tecer" (unweaving) e para também "des-dizer" (unsaying) o mundo/o real, o que inclui des-tecer e des-dizer a própria identidade, essa "Me-Myself-and-I" que é, ela própria, uma construção: uma energia em processo, em trabalho, dentro do sistema que é a própria obra (neste caso, literária) e a qual inclui o autor - ou seja, para voltar à termodinâmica, a energia de activação da reacção.

Se bem entendi, usando agora a uma linguagem científica para representar esta realidade, trata-se de entalpia, uma medida termodinâmica equivalente ao calor de um sistema, ou seja, a energia interna do sistema, mais o produto. O problema é que qualquer aumento - ou transformação positiva - de volume resulta sempre numa emissão de trabalho pelo sistema, ou seja, numa perda de energia interna. Isto significa que só 
se torna possível medir a energia útil de um sistema químico, pois a entalpia total é impossível de calcular. Ao que fica de fora, chama Robert Duncan o "it". E para encontrar "o como" o ver, como fazer a pergunta a ser feita, Duncan diz: "I want to catch myself out" (Duncan 1985c: 231): quero "apanhar-me”, "ver-me”, lá fora. Fora do que chama o sistema multifásico de "pessoalizações, personificações, transpessoalizações e despessoalizações" ("impersonations, personifications, transpersonations and depersonations") que, segundo ele, desde os primeiros níveis de desenvolvimento da sua linguagem (do seu primeiro corpo de afirmações, digo, com Feynman) estiveram sempre "em jogo" (idem: 220).

Este é um desejo pelo “'eu'-fora-de-toda-a-performatividade”, por um “'eu'-nãoútil”, um "eu" que se dissolve no "it" - um desejo por uma impossibilidade, já que, precisamente por se estar dentro, a entalpia total é impossível de calcular. Sabendo isso e consciente da inevitabilidade da performatividade - pela consciência aguda da linguagem como um jogo de representações, um jogo de implicações sociais e políticas e, no seu caso, implicações sexuais - a poesia de Robert Duncan só pode ser ser considerada“pós-moderna", no sentido lyotardiano e butleriano do termo (Lyotard 1989; Butler 2006).

Tal como pós-moderno é Jess, o companheiro de Duncan, artista plástico e também cientista, químico que trabalhou na produção de plutónio no Manhatan Project e no Hanford Atomic Energy Project e que, perante o desastre da bomba atómica, decidiu, em 1946, afastar-se da ciência e dedicar-se às artes plásticas, nomeadamente a um trabalho a que chamava Paste-Ups. Diz Jess, numa das suas únicas entrevistas:

I think the "Paste-Ups" might also relate to Robert's ideas about poetry and rhythms and the mixing of themes. None of this was conscious, but we often talked about the element of surprise and disjunction in forming an image. When I am pasting up, I am moving images around constantly, surprising myself with new meanings. (Jess in Auping 1993: 24-25)

E, um pouco mais adiante na entrevista, afirma:

(...) it must all remain in flux so that no single story dominates (...) I really would not want to tell you what I see and that often changes anyway - because that would limit your seeing. (...) the mythic imagination carries a level of reality that can be equal to or greater than logic and the scientific method. I try to bring together many story possibilities that will trigger more stories and more possibilities. (...) creating something that does not stop where my imagination leaves off. (idem: 26)

Na mesma linha, atrevo-me a dizer que também Feynman é um digno representante de uma ciência pós-moderna. Claramente partilhando este modelo de representação agonista - e não colaborativo - de linguagem de Duncan e de Jess, eis como Feynman 
nos traz esta mesma questão em palavras que são bem exemplo de um "pensamento tropical” (de resto, o físico viveu durante algum tempo no Brasil): “(...) os antigos acreditavam que a Terra era o traseiro de um elefante que estava por cima de uma tartaruga que nadava num mar sem fundo. É claro que o que sustentava o mar era outra questão, cuja resposta ignoravam" (Feynman 1998: 20). Proponho chamar a essa desconhecida sustentação do mar o "it" de que fala Duncan - e que a medida da entalpia não nos consegue dar - ou seja, o que nos permitiria chegar ao sentido de tudo. Mas Feynman continua:

Esta crença dos antigos era produto da sua imaginação. Era uma bela ideia poética. Agora vejam como a encaramos hoje. Será uma ideia aborrecida? O mundo é uma bola que gira e as pessoas estão agarradas a ela por todos os lados, algumas de cabeça para baixo. E giramos como um espeto em torno de uma enorme fogueira. Giramos à roda do Sol. Isto é mais romântico, mais excitante. E o que nos mantém? A força da gravitação, que é algo que não é apenas da Terra, mas é o que antes de mais faz a Terra ser redonda, sustenta o Sol e nos mantém a rodar à volta do Sol na nossa perpétua tentativa de nos afastarmos. Esta gravidade exerce o seu poder não só sobre as estrelas, mas também entre as próprias estrelas; mantém-nas nas grandes galáxias ao longo de quilómetros e quilómetros em todas as direcções.

Este universo já foi descrito por muita gente, mas os seus limites continuam a ser tão desconhecidos como o fundo do mar sem fundo da outra ideia - precisamente tão misterioso, tão inquietante e tão incompleto como as descrições poéticas que o antecederam. (idem: 20)

Eu talvez acrescentasse: "como também as outras descrições científicas que o antecederam". É por isto que Feynman pensa tropicalmente.

E porquê toda esta minha reflexão para falar de "Tommy goes out into the night to seek an elf"? Por causa de um título de índole, por um lado, tão fantasiosa e, por outro, de jogo sexual quase explícito (do cruising gay), por que razão me pus à procura de textos de índole científica - que deveriam ser, precisamente, o oposto de fantasia e de jogo sexual?

Precisamente por causa da expressão "the dissolution of the physical chemical universe”, que Duncan relaciona com o “eu”, com o "self” (Duncan 1985c: 233). De repente, partindo da minha mais que absoluta ignorância, vi-me obrigada a ir ao Google... e a não saber sequer como procurar. E, quanto mais hipóteses de buscas formulava (quanto mais dava forma a outras perguntas), mais perguntas e formas de perguntar me surgiam... Achei que o melhor - para descobrir, finalmente, o que seria a "dissolução" do universo - era ir ler um livro que tinha por título O Significado de Tudo de Richard Feynman. Não encontrei a resposta, como já se deve ter percebido, mas encontrei uma reflexão que me obrigou a pensar no "como saber como saber". Foi a primeira etapa.

A segunda etapa foi telefonar a uma amiga, a Maria da Conceição Ruivo, que é física teórica e escritora de livros de ficção e de literatura infantil bastante poética - e esperar que ela conseguisse que eu percebesse alguma coisa do que tinha andado a ler pelo Google e 
pelo Feynman. O que ela me ajudou a perceber - e o agradecimento aqui lhe fica por isso - é que cada transformação no sistema faz com que a energia seja cada vez menos útil, pois há uma perda de ordem, uma perda de poder para que o sistema funcione. A isso chama-se entropia. E assim se fez luz, pois Duncan considera que a dissolução do "Me-Myself-and-l" é apenas uma participação na dissolução do universo físico-químico, ou seja, quando o sistema se dissolve, sabemos que a energia se traduz numa variação, que a energia que se perde está num exterior - ou seja, simplesmente, não sabemos onde está esse "It" que sustenta o mar sem fundo onde nadamos, para voltar à metáfora de Feynman.

Robert Duncan e Jess, como muitos artistas desde o início do século XX, estiveram sempre muito atentos às descobertas do que Duncan chamou uma ciência criativa, por oposição a uma ciência dita de pés na terra, que entendia como estando ao serviço dos grandes interesses do capital (Duncan 1985a). Desde o princípio da incerteza à teoria da relatividade, da singularidade matemática à mecânica quântica, da teoria do caos à teoria das cordas - muitas foram as apropriações e/ou as "traduções" trabalhadas pela arte e pela literatura contemporâneas. Fala-se hoje, na crítica literária, em poéticas quânticas ou poema-onda. Robert Duncan é disso um bom exemplo também, tendo-me obrigado a muitas leituras fora do domínio da poética.

Também Jess, nas suas obras, divididas em "Non-Objective and Romantic Works", "Translations", "Paste-Ups" e "Salvages", tenta fundir a sua linguagem científica e a sua linguagem artística com outras linguagens, como, por exemplo, a da poesia. ${ }^{1}$ Dizia que tinha chegado à pintura tarde e que só podia levar o seu pincel ou o seu lápis por cima do que os outros pintores já tinham feito - e "des-re-fazer", impondo-se (a si, ao seu "Me-Myself-and-I") sobre a imagem, criando o que poderemos considerar o forçar do erro por cima da representação e/ou das imagem existentes - para, dessa transformação, criar ideias novas: do real e de si próprio. A verdade é que existe toda uma teoria do erro na obra de Jess e de Duncan. É isso que podemos encontrar numa sobreposição de imagens em collage (e vários instrumentos científicos, como um armário de química, aparecem no meio de representações de mitos ou objectos do quotidiano) ou como uma tinta espessa surge, quase a borrar o original (às vezes, já um original próprio, como acontece em "Salvages", em que se recuperam e refazem o que já são as suas próprias obras); ou ver, em "Translations", como a imagem, que é também visual, das letras da poesia se funde com outras imagens visuais.

De facto, ambos os artistas estavam envolvidos no que chamavam o projecto de uma grand collage que, no dizer de Duncan, traria todas as peças de todos os puzzles construídos para representar o real (ou seja, todas as linguagens de todas as áreas do saber) para cima de uma única mesa, em que teríamos, sem quaisquer hierarquias do saber, de começar a construir a representação mais inclusiva e mais democrática e, nesse sentido, mais verdadeira (Duncan 1985a). 
Claro que a totalização do discurso, a totalização da representação, nunca será possível (medir a entalpia total de um sistema é impossível, já sabemos), e apenas nesse campo em aberto (a base da chamada "open field theory"), sempre em movimento (e a grand collage acaba por se transformar num móbil), se pode tentar tornar presente a diversidade e a multiplicidade de verdades: aquilo que, no dizer de Feynman, podemos traduzir como todo "um corpo de todas as afirmações com diversos graus de certeza" - e todas as perguntas e as novas afirmações por fazer. Cito Feynman, uma vez mais, quase ecoando a poética do campo aberto:

O sonho é encontrar a via aberta. Qual é então o significado de tudo? O que é que podemos dizer hoje para desvendar o mistério da existência? Se tivermos tudo em conta, não apenas o que os antigos sabiam, mas também tudo o que descobrimos até hoje e que eles desconheciam, temos de admitir que não sabemos responder a esta questão. Mas acho que, ao admitirmos isto, estamos, provavelmente, a encontrar a via aberta. (Feynman 1998: 43)

Não era já São Tomás de Aquino que nos falava no estarmos “in via”, como prova infalível de que a Morte não existe como Absoluto?

Dois homossexuais assumidos, a viver juntos entre 1951 e 1988 (ano da morte de Duncan), Duncan e Jess estariam bem cientes, nas suas próprias vidas e nas suas próprias identidades, da violência da linguagem de uma comunidade que não lhes permitia sequer uma qualquer forma de representação e/ou de visibilidade públicas - enquanto sujeitos, enquanto artistas e/ou enquanto cidadãos. De facto, a sua casa em S. Francisco transformara-se numa espécie de sede para a formação de toda uma geração norte-americana de activismo social e político, que era também - e como poderia deixar de sê-lo? - um activismo artístico, em prol dos direitos civis, dos direitos sexuais, dos direitos humanos. Muitos intelectuais encontraram, nesse espaço, o espaço de divulgação científica que o McCarthyismo e a perseguição aos Reds lhes retirara, substituindo as salas de aula (de onde tinham sido expulsos) pela mesa da cozinha de Jess e de Duncan, onde agora os seus jovens alunos os procuravam. A ordem do universo era assim, para ambos, tão importante como a ordem da sua vivência e do seu espaço domésticos (a sua household): parte do que permitia a vida a fazer-se. Diria que se tratou de um activismo em prol do direito a uma linguagem: a uma e a qualquer linguagem - que o mesmo é dizer, a uma e qualquer representação. Porque sem representação, como sabemos, não há poder. Por isso, a San Francisco Renaissance e a Beat Generation, de que Duncan e Jess foram mentores (também na sua relação, enquanto alunos, primeiro, e professores, depois, com a experiência interartística que foi Black Mountain College), acabaram por surgir como formas de capacitação: de encontrar a representação visível a partir da qual a acção (a questionação, as perguntas por fazer, a resistência, a via aberta) se tornou possível. 0 trabalho artístico de ambos teve que ser, forçosamente, um trabalho de "des-tecer" e "des-dizer", pois não era possível, para qualquer um dos dois, pensar uma estética fora de uma sociedade, fora 
de uma sexualidade e fora de uma política. Afinal, a sua identidade construira-se, por assim dizer, como uma identidade pela negativa, por isso, uma identidade que não perde nunca a consciência de que há uma energia que sustenta o mar onde nadamos e que lhe é exterior. A não-utilidade dessa energia criativa, que não é útil para o sistema económico, social ou político, quer da perspectiva sexual quer da perspectiva da hierarquia dos saberes instituída, é, no entanto, aquilo que lhes dá existência como seres humanos e/ou como criadores. É a partir desse "It", nele e com ele, na consubstancialidade com o todo da energia em processo, que a identidade, a linguagem e o entendimento do mundo se constroem: "the first person, the second person, third person, and "it" in a round", diz Duncan (Duncan 1985c: 220). A roda das crianças surge num quadro de Jess - a mesma roda que irá ilustrar a capa do livro da maturidade poética do Duncan, Opening of the Field. ${ }^{2}$ Afinal, "O sonho é encontrar a via aberta", como disse Feynman.

Em "The Self in Postmodern Poetry", de Duncan, descobrimos que é Jess quem recorda a Duncan que a frase "Tommy goes out into the night to seek an elf" se encontra num livro de histórias para crianças, "The Owl's Answer to Tommy", em My Bookhouse, de Juliana Horatia Ewing, autora inglesa do final do século XIX, que parece ter encontrado o lacaniano "estádio do espelho" avant-la-lettre (e, curiosamente, descobri que, em sistemas computacionais, há também um "ELF": Extensible Linking Format...). Conta a história que Tommy quer encontrar um elfo para enfeitar e para ajudar na casa da avó. Uma coruja ensina-lhe um feitiço, que Tommy deve repetir enquanto roda em torno de si próprio junto ao lado norte do lago. Ao terminar, deve olhar para o lago profundo e pensar numa palavra que rime com "elf”. Não descobre a palavra, mas, ao olhar para o lago, vê-se a si próprio: a sua representação, a sua imagem, e não o "Self”/"Elf" verdadeiro.

Trata-se de uma história sobre Eco e Narciso, ou seja, sobre a necessidade de encontrar a linguagem de si (Self), que afinal não se encontrará, pois tudo não passa de um espelho, de um eco, de um reflexo. Tommy não consegue ouvir a palavra que rima verdadeiramente com "Self" pois essa fica no "It", fora da linguagem do reflexo, fora do que o lago lhe devolve. Não é a imagem de si no fundo profundo do lago, no que sustenta a água: é apenas uma representação, a linguagem.

Educado no seio de uma família teosofista, eis como Duncan explica a criação literária: "The Great Writers (...) They lost themselves, theirselves, in their work. Here 'self' disappears and 'work appears" (Duncan 1985c: 225)". Tentando traduzir, agora com uma outra linguagem: um aumento de trabalho de um sistema ("work appears") significa uma perda de energia interna ("self disappears"). Por isso, a criação, a arte, procurando o verdadeiro "Self" - o "Self" com letra maiúscula que se manifesta na palavra movendo a partir de dentro para criar som, energia a produzir forma, tem de se definir forçosamente como um "des-dizer", um "des-tecer", um "des-fazer" de si. Assim sendo, o conhecimento de si é um "Sublime Undoing", nas palavras do poeta (idem: 234). Veja-se o quadro intencionalmente inacabado que Jess nos deixou, Narkissus ${ }^{3}$ : criar é procurar a dissolução, não só das formas que o sistema social legitima, mas também de todas as 
outras formas encontradas. Partilhamos, na expansão da nossa consciência, a expansão do próprio universo que, perdendo calor nesse trabalho, acabará por se dissolver - no nada ou noutra coisa qualquer. Mas lançamo-nos - estamos sempre a lançar-nos - na via aberta, pelo desejo de encontrar a totalização, o fecho, a resposta definitiva.

$\mathrm{Na}$ arte, como na ciência, há que continuar a projecção de si no Outro - passe a tautologia: em toda a alteridade do infinitamente Outro de que sabemos fazer parte, até que deixe de haver reflexo, pois como Feynman, Duncan e Jess bem sabiam: "In this longing for the close, the Me-Myself-and-I trinity is dissolved", "the dissolution of the physical chemical universe which I take to be the very spiritual ground and body of our being" (Duncan 1985c: 234, 233).

\section{NOTAS}

* Graça Capinha é Professora Auxiliar do Departamento de Línguas, Literaturas e Culturas (DLLC), Secção de Estudos Anglo-Americanos, na Faculdade de Letras da Universidade de Coimbra (FLUC), Investigadora Sénior do Centro de Estudos Sociais-Laboratório Associado (CES) e colaboradora do Instituto de Literatura Comparada Margarida Losa, da Faculdade de Letras da Universidade do Porto. É co-directora do Programa de Doutoramento inter- e transdisciplinar "Discursos: Cultura, História e Sociedade” (FLUC/FEUC/CES). Entre 1991 e 1999, esteve ligada ao Poetics Program, da State University of New York (SUNY at Buffalo), aí tendo trabalhado com alguns nomes da teoria $L=A=N=G=U=A=G=E$. Co-organizadora dos "Encontros Internacionais de Poetas" da FLUC (1992-2001), dirigiu a Oficina de Poesia. Revista da Palavra e da Imagem (1997-2013), integrando actualmente o Conselho Editorial da Colecção Almedina/CES.

${ }^{1}$ Cf. https://jesscollins.org

${ }^{2}$ Cf. An Opening of the Field (https://lib.store.yahoo.net/lib/pomegranate/a220.pdf)

${ }^{3}$ Cf. https://www.sfmoma.org/artwork/96.492/ 


\section{BIBLIOGRAFIA}

Auping, Michael (1993), JESS. A Grand Collage 1951-1993. Buffalo, the Albright-Knox Art Gallery.

Bernstein, Charles (1992), A Poetics. Cambridge, Harvard University Press.

Butler, Judith (2006 [1990]), Gender Trouble: Feminism and the Subversion of Identity. New York: Routledge.

Duncan, Michael /Michael Wagstaff (2013), An Opening of the Field. Jess, Robert Duncan, and Their Circle. Portland, Pomegranate \& Crocker Art Museum.

Duncan, Robert (1985a), "The Truth and Life of Myth. An Essay in Essential Autobiography". In Robert Duncan, Fictive Certainties. New York, New Directions, 1-59.

-- (1985b), "Ideas of the Meaning of Form". In Robert Duncan, Fictive Certainties. New York, New Directions, 89-105.

-- (1985c), "The Self in Postmodern Poetry", In Robert Duncan, Fictive Certainties. New York, New Directions, 219-234.

Feynman, Richard P. (2001 [1998]), O significado de tudo. Reflexões de um cidadãocientista. Lisboa, Gradiva [1998].

Foucault, Michel (2014 [1966]), As Palavras e as Coisas. Lisboa, Edições 70.

Lecercle, Jean-Jacques (1990), The Violence of Language. New York, Routledge.

Lyotard, Jean-François (1989), A condição pós-moderna. Lisboa, Gradiva.

Santos, Boaventura Sousa (2010), "Para além do pensamento abissal: das linhas globais a uma ecologia dos saberes”. In Boaventura de Sousa Santos \& Maria Paula Meneses, Epistemologias do Sul. São Paulo, Cortez, 31-83.

Taussig, Michael (2010), The Devil and Commodity Fetishism in South America. Chapel Hill, University of North Carolina Press. 